\title{
Kutsal ve Seküler Arasında: Hıdrellez ve Türbe Kültleri Çevresinde Gelişen Eğlence Kültürüi
}

\section{Mustafa ARSLAN ${ }^{1}$}

Öz: Makalede Türk manevi halk inançlarında en önemli iki figür olan Hıdrellez ve Türbe ziyareti çevresinde meydana gelen eğlence kültürü konu edilecek, kutsal-profan dikotomisi çerçevesinde konunun önemli noktalarına değinilecektir. Biz daha önceki bir çalışmamızda Türk halk inançlarının önemli figürleri arasında evliya kültü (türbe ziyareti vb.) ve mitolojik boyut olarak da hıdrellez kültünün olduğunu tespit etmiş̧tik. Bu figürler halk inançlarının senkretik niteliğiyle de paralellik arz etmektedir. Kutsalın tezahürü olarak oluşan (hiyerofani) bu iki inanç ve ritüelin etrafındaki oldukça zengin ve seküler eğlence kültürünü görmek ilginç olacaktır. Çünkü Türk kültüründe türbe ziyareti ve hıdrellez kültü çevresinde oluşan inanç ve ritüellere bakıldığında orada eğlenceleri de görmekteyiz. Burada kutsal çevresinde oluşan seküler bir olgunun çeşitli yönlerini görmek din fenomenolojisi açısından da önemlidir. Bu eğlencelerin "kutsal" ve "seküler" niteliklerine değinilecektir. Makalede her iki ritüel çevresinde oluşan eğlence kültürü ayrı ayrı değerlendirilecek ve din ve toplum-grup hayatı içindeki işlevlerine değinilecektir. Konu geniş olacağı için bilimsel olarak iki ilimiz (Malatya ve Çorum) örneklem olarak alınmıştır. Bu iki ilimizdeki örneklere yoğunlaşılacak, sonuçta buradaki uygulamalarla kutsalla ilişkili kutsalprofan/seküler ayrımı vb. teorik konuların karşılaştırmasına gidilecektir.

1 Prof. Dr. İnönü Üniversitesi Felsefe ve Din Bilimleri Bölümü Din Sosyolojisi Anabilim Dalı.mustafa.arslan@inonu.edu.tr 
Anahtar kelimeler: Kutsal, Seküler, Eğlence, Hıdrellez ve Ziyaret kültü

\section{Giriş}

Makalenin konusunu Türk manevi halk inançlarında merkezi iki figür olan Hıdrellez ve Türbe ziyareti çevresinde meydana gelen eğlence kültürü oluşturmaktadır. Dolayısıyla makale kuramsal açıdan "kutsal-seküler ve eğlence kültürü"; pratik açıdan da "Hıdırellez ve ziyaret kültleri” kavramlarına dayanmaktadır. Hıdrellez ve Türbe ziyareti çevresindeki uygulamalarda Malatya ve Çorum illeri örneklem olarak alınmıştır. Buradaki bulgular tarafımızdan bizzat gözlem ve katılım yolu ile farklı zamanlarda (2008-2014 yılları arası) elde edilmiştir.

Kutsal ve seküler (profan) kavramı, dini folklor ve din fenomenolojisinin de içinde olduğu Dinbilimlerinin (Religionswissenschaft) temel kavramlarından olup literatürde dikotomik bir perspektifle ele alınırlar. (Dinbilimleri diğer alt branşları din sosyolojisi ve antropolojisi, dinler tarihi ve din psikolojisidir.) Kutsal olanla seküler-profan olan birbirlerine mesafeli hatta karşıt olarak konumlanır. Ancak bazı örnekler vardır ki seküler-profan olanla iç içe bir görünüm arz eder. Ancak literatürde bunun üzerinde pek durulmadığ 1 görülmektedir. İşte biz bu çalışmada üzerinde pek durulmayan ama literatürün temel kavramlarının bir özelliğini tamamlayan hatta kutsal-seküler (profan) dikotomik teorisinde yeniden düşünmeyi gerektirecek bir konuyu makale imkanları çerçevesinde ele alamaya çalışacağı.

\section{Kutsal- Seküler (Profan) Dikotomisi}

Kutsal din tanımlarının merkezinde yer alan bir kavramdır. Otto'ya göre "Din, korkutucu ve büyüleyici sır (mystérium tremendum fasinosum)" olarak açıkladığı kutsalın tecrübesidir (Otto, 1925).” Otto, kutsala ilişkin tecrübeleri Kantçı bir yaklaşımla numen'le yani görünmeyen, gizemli olanla ilişkilendirir. Numen'e ilişkin olan adeta bir ganz andre’ymiş, yani kökten ve tamamen farklı bir şeymiş gibi özel bir hal almakta, beşeri veya kozmik hiçbir şeye benzememektedir. Bu farklılık 
Otto'ya göre, ondaki müphem (ambigue) karakteristiğinden ileri gelmektedir. Ancak bu müphemlik, birçok tezahür biçimlerinde dikotomik yansımalara sahiptir.

Mircea Eliade da kutsalı tanımlarken kutsal -profan ayrımına gider (Eliade, 1959; 1991). İnsan kutsalın bilincine varır. Çünkü bu kendisini dindışı olandan tamamen farklı bir şekilde gösterir. Kutsal, günlük hayatın normal rutinlerinin dişında duran fevkalâde bir şey olarak alg1lanmaktadır. Kutsal ve profan/seküler arasındaki ayrımı başka düşünürlerde de görürüz. Örneğin Durkheim'e göre, dini düşüncenin ayırt edici özelliği kutsal-profan ayrımında yatmaktadır (Durkheim, 2005). Durkheim ünlü dinbilimci Robertson Smith'in etkisiyle kutsal-profan ayrımına önem vermiştir.

Burada kutsalın diyalektik özelliğine dikkat etmek gerekir. Bunu Durkheim (2005) şu meşhur kutsal tanımında şöyle ifade etmiştir. "Kutsal nesneler, tanrı, ruh gibi isimlendirilen varlıklardan ibaret değildir. Bir kaya, bir ağaç, bir su kaynağı, küçük bir taş, bir ağaç parçası, bir ev hâsılı herhangi bir şey kutsal olabilir. Bir ritüel kutsallığa sahip olabilir. Gerçekte ise belli bir dereceye kadar da olsa kutsallık içermeyen hiçbir ritüel yoktur.” Dolayısıyla ilk başta profan-seküler olan bir şey ileride "kutsal" olabilir. Ancak kutsal olduğunda profan-seküler özelliğini kaybeder. Başka bir nesne olur. Başka bir anlam ve içerik kazanmış olur. Burada bu diyalektiğe bakıp kutsalın profanla yakınlaştığını veya iç içe olduğu zannetmek hata olur. İkisi birbirinden tamamen "ayrı ve bambaşka"dır. Kutsal bir nesnenin önceden profan olması, onun sonraları profan ile ilişkisi olacağını, olduğunu göstermez.

\section{Kutsalı Tezahür Ettiği, Tecrübe Edildiği Zaman ve Mekan:}

\section{Kutsal Zaman-Kutsal Mekan}

Görüldüğü gibi kutsal seküler-profan olandan ayrıdır ve farklı biçimde tezahür eder. Bu profan-seküler alandan farklı olarak kutsal, farklı yani "kutsal bir zaman ve mekân "da tezahür eder. Dolasıyla Dinbilimleri literatürüne göre, kutsal kavramını anlamak için birinci adım 
onun profan-seküler alandan farklılığına dikkat etmek; ikinci adım ise onu "kutsal mekân ve zaman" kavramları ile birlikte anlamaktır. Kutsal mekânlar ve zamanlar, bizi kutsalın dünyasına götürürler (Pettazzoni, 2002). "Kutsal mekân", kutsal, aşkın olanla iletişim kurulabilen bir “merkez"dir (Eliade, 1991).

Dolayısıyla kutsal, belirli "kutsal bir zaman" veya "belirli kutsal bir mekân"da tezahür etmekte veya tecrübe edilebilmektedir. Bu büyük dinlerde olduğu gibi küçük kültler için de söz konusudur. Konumuz olan "hıdrellez kutsal bir zaman"1, "türbe de kutsal bir mekân"1 ifade etmekte ve bu bağlamda kutsalın tecrübesi gerçekleşmektedir. Kutsal mekân "aşkın" ve "bambaşka" olan kutsalı tecrübe etmek için merkez olurken kutsal zaman da kutsalı tecrübe etmenin anıdır. "Kutsal zaman"ın devrevi zamanları vardır. Dindar insanın anlayışında zaman yıllık olarak yenilenir. Kutsal zaman, insanı ilk mitik an ile yeniden bütünleştirir (Eliade, 1991). İnsan baharın gelişi ile doğanın yeniden canlanışının bir kutlaması olan Nevruz ya da Hıdrellez ile aslında "zamanın yeniden başlangıcına" ve ayrıca "evrenin yaratılışının yeniden güncellenmesine" katılmış olur. Başka bir deyişle kutsal zamanın insan için simgesel anlamı, yeniden doğuş ve yeniden yaratılıştır ve bu sayede insan "kutsal ve güçlü zaman" ile yeniden bütünleşmiş olmaktadır. Eliade’a göre periyodik olarak ortaya çıkan yeniden doğuş sürekli her kültürde görülebilmektedir (Eliade, 1994).

Kutsalın tezahürü ve deneyiminde diğer iki kavram "mit ve ritüel” kavramlarıdır. "Ritüel” kutsalın belli bir zaman ve mekânda tecrübe edilmesidir. "Mit" ise kutsal bir tarihi ifade eder, zamanın başlang1cında meydana gelmiş bir ilk olayı atıftır. Kutsal zamanı anmak, kutlama yapmak, hem evrenin yeniden doğuş ve yaratılışına simgesel bir katılış, hem de mitleri "yeniden güncelleyerek" kutsalı tecrübe etmek ve kutsallığa "katılmaktır" (Eliade, 1991). Dolayısıyla kutsal zamanda yapılacak bir kutsal deneyimi için bu deneyimin ilk olayına, anına gitmek için mite ihtiyaç vardır. Başka bir deyişle ritüelin deneyimi için onu bir ilk nedene bağlayan kutsal anlatıdır. Ritüel, mitten çıkarılan ve onunla ilişkilendirilen semboller ile kutsal bir zaman ve mekânda ifa edilir. 
Hıdrellez buna çok güzel bir örnektir. Burada yeni yılla ilgili mitler anlatılır. Mitteki ritler tekrarlanır. Böylelikle dünyanın sanki yeniden başlaması tecrübe edilmiş olur. Zamanın yeni bir çevrimi sanki yeniden resmen başlatılmış olur.

\section{Seküler bir Kategori Olarak Eğlence}

Eğlence, sözlük anlamında hoşça vakit geçirme işi, bu maksatla düzenlenen toplantı, gönül eğlendiren, hoşça vakit geçirten şey şeklinde tanımlanmaktadır. Erol Güngör'e (1981) göre eğlence, her şeyden önce bir heyecan hali, gayesi haz vermek olan bir davranış, gerçek hayattaki engellemelere, hayal kırıklıklarına karsı bir çeşit sığınak ve realitenin sıkıntılarından kurtulma çabasıdır. Bu anlamda eğlence dini olandan çok dünyevi-seküler alana ait bir kavram olarak görünmektedir.

Eğlence sadece basit bir şey olmayıp bireyin hayatında farklı işlevlere sahiptir. Kültürel, ekonomik, siyasal sosyal ve psikolojik işlevleri söz konudur (Tuzcuoğlu, 2008). Örneğin öncelikle dini-milli-yerel bir anlamı olan eğlence sonraları siyasi ve kimliksel bir özellik kazanabilir. İlk çağlardan bu yana dini ve ekonomik yönü olan Nevruz kutlamalarının sonradan siyasi anlamlara sahip olduğunu biliyoruz. Yine bahar bayramı gibi kutlanan Hıdırellez'in bazı Alevi topluluklar için topluluğun kimliğini tahkim etmek gibi işlevleri söz konusudur. Yine bazı türbeler etrafındaki anma ve kutlanmalar o çevrenin ekonomik refahına dönemlik katkılar sunmaktadır. Kültürel açıdan eğlenceler toplumların bir araya gelmelerine, insanlar arasında pozitif iletişim ve etkileşim ortamlarının oluşmasına imkân sağlamaya, ortak duygu ve davranış tarzlarının doğmasına sebep olmaktadır.

Dini açıdan eğlenceye bakıldığında, her ne kadar eğlence ilk başta dünyevi, seküler bir alan olarak görülse de, insani yönlere hitap etmesi açısından dinlerin eğlenceyi tamamen dışlaması pek mümkün olmaz. Çünkü dini oluşturan gruplar da insanlardan oluşmaktadır. Ancak dini veya mezhep görüşlerine göre dindar insanın eğlence anlayışında farklılıklar olur. Kişilerin dini kabulleri eğlenceye bakışlarını etkilemektedir. Dindar insan açısından eğlence onun kutsala bakışı ve yaklaşımı 
ile paralel; kimi zaman da kutsala ilişkin bir mit ya da ritüeli tamamlayıcı biçimde olmalıdır.

\section{Kutsal ile Seküler Arasında: Hıdrellez ve Türbe Kültleri Çevresinde Gelişen Eğlence Kültürü}

Eğlence ve kutlamaların görüldüğü gibi kutsal ve dini olanla da alakaları olabilmektedir. Her ne kadar teoride alakasız gibi görülse de uygulamada buna dair örneklere -tabi kutsalla ilişkisi nispetinde- rastlanılmaktadır. Bu ikisi arasındaki karşılıklı ilişkiye bazı çalışmalardan örnekler verebiliriz. Örneğin Chidester ve Linenthal (1995) kutsal ve profanın zorunlu olarak birbirini dışlamadığını, iç içe veya yan yana olduğu durumların da olabildiğini gözlemlemişlerdir. Onlara göre "Kutsal mekânlar" hem kutsalı hem de profan aktivitelerin içinde yer bulduğu karmaşı mekânlar olabilmektedir. Chidester and Linenthal, Hawai de gündüz halka açık olan bir mekânın saatler sonra kutsal bir mekân olarak hizmet gördüğünü ve geleneksel ritüellerin yapıldığ 1 yere dönüştüğünü gözlemlemişlerdir. Yine Özdemir (1999) Hıdrellez inancı çerçevesinde Anadolu’nun farklı bölgelerinde kutlamaların olduğunu tespit etmiştir.

Bizim gözlemlerimiz de Hıdırellez inancı çevresinde bazı eğlence ve kutlamaların yapıldı̆̆ 1 şeklindedir. Malatya ve Çorum illeri çerçevesinde konuyu örneklendirmek istiyoruz.

Çorum'da Hıdrellez inancı ve ona bağlı merasimler şehirleşme sürecine rağmen canlı bir şekilde yaşanmaktadır. Hıdrellez kültü etrafında şekillenen inanışlarda "eski kültürlerin izlerinden, İslamiyet'ten, eski Türk geleneklerinden gelen birçok öğe bir arada bulunmaktadır (bkz. Ocak, 1988; 1990). Hıdrellez Çorum'da, dışarıda yeşillik bir yerde, bazen evde, türbe ziyareti ile veya dilek dileyerek ve adak adayarak kutlanmaktadır. Sünni ve Alevilerin ortak kutlamaları olmakta, ayrıca Aleviler arasında müsait yerlerde semah da oynanmaktadır. Hıdrellez kutlamalarında toplu törenlerin yapılacağı, adak ya da dileklerin yapılacağı bir mekân önem arz etmektedir. Günümüzde Anadolu’nun çeşitli yerlerinde Hızır/Hıdır adını taşıyan birçok adak yeri, halk tarafından 
ziyaret edilmekte, dilek dilenip adak adanmakta, kurban kesilmekte ve çeşitli törenler düzenlenmektedir. Çorum'daki bu mekânın adı Hıdırlık Sultan mevkiidir. Hıdrellez Beş Mayıs günü (diğer yeşillik yerler yanında) en çok bu yere insanlar rağbet göstermekte, buraya gelerek hem Hıdırellez gününün özelliği olan yeşillik yerde piknik yapmakta, hem de buradaki türbeleri ziyaret etmektedirler. O gün temizlik yapıp, yiyecek ve içecek hazırlama gibi işlerle başlayan Hıdırellez merasimleri çeşitli dilekleri hedefleyerek yapılmaktadır. Bu tarz dilekleri olanlar bir gece öncesinden dileklerini bir kâğıt üzerine resmederek veya dileğinin (ev, araba vb.) bir benzerinin maketini yaparak yeşilliğe ya da bir gül fidanının dibine koyarak Hızır’n buraya uğrayacağına ve dileklerini kabul edeceğine inanmaktadırlar.

Hıdırellez zamanındaki inanış ve uygulamalar yanında kutlama ve eğlenceler de söz konusudur. Çorum kent merkezinde yaptığımız uygulamalı çalışmada Hıdrellez gününün manevi-kutsi anlamı olduğunu söyleyenler \%58, neşe ve eğlence günü olduğunu söyleyenler ise $\% 24$ oranında çıkmıştır. Buradan bir kısım insanların Hıdırellez algısının sadece eğlence olduğu anlaşılmaktadır.

Çorum'da halk arasında "Hıdırellez günü mutlaka dışarı çıkarak Hıdrellezi kutlamak, eğlenmek, o günü eğlenceli geçirmek” gerektiğine inanılmaktadır. Böyle yapılırsa o senenin mutlu ve sağlıklı geçeceği, "Hıdrellez günü ne yaparsan bütün seneyi o şekilde geçirirsin" inancı Çorum'da hâkimdir. Dolayısıyla eğer kişi Hıdrellezi çoluk çocuğuyla birlik beraberlik ve neşe içinde dışarıda, yeşillik bir yerde kutlayarak geçirirse o senenin de o şekilde mutlu, sağlıklı ve neşeli geçeceği inancı hâkimdir. Bu inanıştan hareketle olsa gerek Hıdırellez ile eğlence "yan yana" anılmaktadır.

Bu inanışa bağlı olarak, Çorum'da halk arasında çoğu kişi Hıdrellez gününü çalışmadan geçirmeye çalışırlar. Çünkü o günü çalışmadan kutlayarak geçirirse, hem o günün bereketine nail olacak hem de bütün seneyi o günkü gibi neşeli, eğlenceli geçirecektir. Biz de, araştırmalarımız sırasında bazı çalışanların sırf Hıdrellez kutlaması için işlerinden özellikle izin aldığını gözlemledik. 
Çorum'da Hıdrellezle ilgili diğer bir inanış ve uygulama, imkânı olan ailelerin nişanlıları dışarı çıkarmaları, dışarıda piknik vb. eğlence ile günün kutlu ve neşeli geçirilmesidir. Böylelikle (inanışa göre) gelin ve damat bereketli bir günde bir araya gelmiş, sonraki evliliklerinin temeli bereket ve hayır üzerine kurulmuş olmaktadır. Ayrıca Hıdrellez şenliklerinde bekâr gençler, kutlamalarda tanışmaları amacıyla diğer günlere oranla daha serbest birakılırlar ki birliktelik bereketli temeller üzerinde olsun.

Çorum'da Hıdırellez’in kutlandığ 1 en merkezi yer Hıdırlık Sultan mevkiidir. Burada üç sahabe mezarı olduğuna inanıldığ 1 için popüler dini kültürün merkezi olmuştur ve hem türbe ziyareti hem de Hidrellez kutlamalarında hizmet görmektedir. İnsanlar Hıdrellezi bu mevkide kutlamakta, türbe ziyaretlerini yapmakta ve burada pikniklerini de yapmaktadırlar. Bunun için piknik yerleri yapılmıştır. Böylece hem manevi hem de eğlence yönü olan bir uygulama gerçekleştirilmektedir. Çorum'da bu yer dışında Başka yeşillik park vb. yerlerde de Hıdrellez kutlanmaktadır. Bu dönemdeki kutlamaları "ikiye" ayırabiliriz. Birincisi hem dilek dileyip türbe ziyareti sonrasi/beraberinde piknik yapanlar; ikincisi sadece müzik vb. eşliğinde piknik yapanlar. İkincisi tamamen seküler bir karakterdedir ve yukarıdaki anket sonucunda da bu durum görülmektedir.

Eğlence kültürünün kutsalla iç içe bir görünüm arz ettiği diğer bir örnek Malatya'da Kernek meydanındaki hidrellez kutlaması ve Malatya Battalgazi' deki Hasan Basri Türbesidir. Bu mekânlardaki gözlem ve deneyimlerimiz 2008 ila 2014 yılları arasına aittir. Özellikle Kernek mekânında 2014 yılı itibarı ile yeni yapılaşmalar olmuştur. Bu yeni durum çalışmamızın dışındadır ve ileriki dönemler için yeni çalışma ve eski ile karşılaştırma fırsatı doğacaktır.

Öncelikle Malatya kent merkezinde Hıdrellez kutlaması mekânı olan Kernek'e bakalım. Malatya' da Hıdrellez için Kernek'in merkez olması, yeşillik olması, su kaynağına sahip oluşu (nisan ayında suyun patlayarak çıkması ve göl oluşturması) ve Kernek Baba gibi evliya kültüne de sahip oluşu gibi nedenlerden kaynaklanmış olmalıdır. Kernek'e bakıldığında 
mekânın Hidrellez kutlamaları dönemi olan 5-7 Mayıs dışında bir eğlence mekanı olduğu görülmektedir. Tarihi sürece bakıldığında mekân, özellikle ellili yıllar öncesinde ve devamında halkın gezme, piknik ve eğlence yeri ve kadınların temizlik mekânı (yıkama vb.) olarak kullanılmaktaydı. Ayrıca sazlı sözlü eğlencelerin, arkadaş toplantılarının yapıldığı, türkülerin söylendiği, dönme dolaplar kurulduğu, bazen köçek oynatıldığg, türlü yemeklerin yenildiği bir "eğlence ve dinlenme mekânı" olarak da işlev görmüştür. Kernek’teki bu eğlence kültürünün yans1ması olarak havuzun yan tarafına çocuklar için dönme dolapların yapıldığı, gençlerin kendilerine kayık yapıp üstten gelen şelaleden aşağıya doğru kaydıkları da bilinmektedir. Kentleşme sürecinin başlarında kadınların Kernek'in suyunu evlerine taşıdığı, yeme ve içmede kullandığı, halı yıkama, yün yıkama, bahar temizliklerini bu sudan yaptıkları ifade edilmiştir.

Mekânın bu ilk dönemine geleneksel dönem diyebiliriz. Kentin modernleşmesi ile özellikle yetmişli yıllardan itibaren mekânda yapılaşmaya gidildiği ve mekânın gazino-park haline dönüştürüldüğü görülmektedir. Burada yaz döneminde önemli milli sanatçıların sahne aldığ 1 diğer zamanlarda eğlencelerin yapıldığı bilinmektedir. Son yıllara kadar mekân bu özelliğini devam ettirmiştir. Günümüzde ise belediye tarafında yeni yapılaşmaya gidilmektedir ancak mekân, eğlence boş vakit geçirme mekânı olarak özelliğini devam ettirmektedir. Dolayısıyla "modern dönem" de de mekân boş vakitlerin değerlendirildiği ve dahası bir eğlence merkezi olarak işlev görmüştür. Bütün bunlardan hareketle, hem modern öncesi "geleneksel” hem de "modern" döneminde Kernek'in "seküler" bir işlev gördüğünü söyleyebiliriz.

Ancak Kernek mekânı sadece seküler bir mekân değildir. Aynı zamanda Hıdrellez kutlamalarının yapıldığı, kendisine halk tarafından bir türbenin de (Kernek Baba) atfedildiği bir "popüler dini mekân"dır. Mekânda Hıdrellez 5-7 Mayıs tarihleri arasında olmaktadır. Son gün ise yoğun bir şekilde kutlanmaktadır. Hıdrellez burada "Beşinde karşılama, altısında kutlama, yedisinde uğurlama” biçiminde bir tekerleme ile ifade edilmektedir. Kutlamalara bakıldığında en yoğun kalabalığın 
gazino içindeki göl alanında olduğu söylenebilir. Göl çevresi tıklım tıklım dolmaktadır. Kutlamalara katılan insanların durumuna bakıldığında kutlamayı, emin biçimde ve kendini kaybeder tarzda yapanlar olduğu gibi, çoğunlukla çekingen, ürkek biçimde ama ssrarla kutlamaya katılıp dileğine yoğunlaşan insanları görmek de mümkün. Bazı insanların kutlamaların yapıldığı göl çevresinde değil de çekinden biçimde dışarıda karanlık olan meydanda şelale çevresinde beklediği ve yatsı ezanı okunur okunmaz dileğini suya bırakıp oradan ayrıldığ 1 da gözlemlenmiştir. Dilekler suya atılırken bazılarının üç İhlâs, bir Fatiha okudukları bilgisi mülakatlarda ortaya çıkmıştır. Kutlamaya katılanların büyük çoğunluğu kadındır ve resmi erkan da (valilik, il kültür müdürlüğü) kutlamaya kapalı mekanda oturarak, halktan ayrı biçimde de olsa, katılmaktadır. Kutlama akşam ezanı ile başlayıp yatsı ezanı ile bitmektedir.

Kernek'teki Hıdrellez kutlamalarına bakıldığında üç figürün öne çıktığı söylenebilir. Öncelikle dar mekânda büyük bir topluluk olmaktadır. İkinci olarak dilek dileme ritüeli farklı şekillerde yapılmaktadır. Bazıları dua mecmuaları, Kur’an vb. metinler okumakta, bazıları göl çevresinde dönerek dilek dilemektedir. En önemli dilek dileme, dileğin kâğıda yazılıp ya da çizilip dişarıdaki şelaledeki "su” ya veyahut göl tarafında park içindeki "gül ağacı" dibine atmaktır. Kâğıttaki dileği özellikle yatsı ezanının okunması ile suya ya da gül ağaçları dibine bırakma toplu biçimde olmaktadır. Herkes ezanı topluca beklemekte ve ezan okunur okunmaz kağıtlar bırakılmakta, böylece ritüel de sonlandırılmaktadır.

Mekândaki diğer bir dilek tipi de mum yakmadır. Orada satılan mumları alarak masalar üzerinde yakılı bekletilmektedir. Mumun masa üzerinde durması için de kum konulma, yakılan mum sönmeden dibine kadar inerse dileğinin kabul edileceğine inanılmaktadır. Mum dikilen masalar, eskiden Kernek babanın mezarının olduğunu düşündükleri "dördüncü çınar ağacın yakınına" veya hemen dibine konulmaktadır.

Diğer bir dilek tipi göl ve Kernek Babanın mezarı olduğuna inanılan dördüncü ulu çınar ağacının çevresinde yapılan dönme (Tavaf) anında yapılan dilektir. Parkta, her bahar başında patlayan su kaynağı, onun oluşturdu göl ve gölün hemen kıyısındaki Kernek Baba'nın mezarının olduğuna inanılan dördüncü sıra ulu ağaçtan oluşan yapı çevresi yedi 
kez dönülmektedir. Dönmenin sonunda dileğin kabul olacağına inanılmaktadır. Dönme ritüeli özellikle türbe, su çeşme ve birikintileri etrafında Anadolu'nun bazı yerlerinde görülmektedir (Tanyu, 1967).

Burada konumuzla alakalı olan yöne dikkatimizi çekmek istiyoruz. Burada "kutsal bir kutlama anında seküler formlarla" karşılaşmaktayız. Öncelikle dilek için okuma ve dilek dileme, mum yakma, dönme vb. şeyler devam ederken aynı zamanda insanlara mekân sahibi tarafından büyük bir dondurma kesilerek ikram edilmekte ine insanlar birbirlerine şeker vb. ikram etmektedir. Bundan da önemlisi yukarıda belirtilen ritler devam ederken mekânda eğlence de devam etmektedir. Bunlar insanların aynı zamanda park yeri olan mekânda masalarda yeme ve içmelerine müzik eşliğinde devam etmesi, yine aynı mekânda çarpışan arabaların yoğun pop müziği eşliğinde hizmete devam etmesidir. Yukarıda açıklanan dileklerini dönerek yaparken insanlar, çarpışan arabaların yanından, gazino parkının masa sandalyelerinin arasından geçmekte ayrıca bu dönme anında parkta disko müzik de çalmakta, çarpışan arabaların eğlencesi devam etmektedir. Dönen insanlar bu durumda dönmelerini tamamlamaktadırlar. Bu karmaşıklık içinde müzikli eğlence çokça garipsenmemekte, Kutsal ve seküler / profan iç içe bir görünüm arz etmektedir. Dolayısıyla burada kutsal seküler iç içeliği ya da etkileşimi iki farklı durumda gerçekleşmektedir:

$i$. Bir eğlence mekânı kutsal bir zamanda (Hıdrellez döneminde) kutsal ritlerin yapıldığ 1 bir geçici mekâna dönmektedir.

ii. İkinci olarak kutlamanın ve dileklerin yapıldı̆̆ı, duaların okunduğu anda da bazı eğlencelerin, müziklerin devam ettiği görülmektedir. Bu her iki farklı durum açısından kutsal-seküler etkileşimi, bir aradalığı söz konusu olmaktadır.

Kutsal ile Seküler iç içeliğini Malatya Battalgazi İlçesindeki Hasan Basri Türbesi çevresinde de görmekteyiz. Battalgazi ilçesinde bulunan sekizgen şeklindeki türbe son yıllarda yapılan çalışmalar ile hem bir türbe ziyareti, hem de bir piknik yapmayı sağlayacak şekilde düzenlenmiştir. Türbe sekizgen şeklinde yapılmıştır. Belediyenin yeni çalışmaları 
ile türbe mekânı aynı zamanda bir piknik, bir mesire yeri olarak düzenlenmiştir. Türbeye gelenler hem dilek dilemekte, dua etmekte, namaz kılmakta ve hatta kurban dahi kesmektedir. Bunlar kutsal ritler olarak Hasan Basri Türbesi çerçevesinde yapılan kutsal içerikli uygulamalardır. Bunları daha ayrıntılı olarak işleyebiliriz ancak konumuz bunlar değil. Konumuz bu kutsal uygulamalar yanında mekân çevresindeki seküler karakterli uygulamalardır. Mekânda insanlar piknik eğlencesi de yapmaktadırlar. Bir araya gelmekte toplu eğlenceler de yapılmaktadır. Hatta insanların bu ihtiyaçlarını karşılamak için türbe çevresi bu şekilde yeniden dizayn edilmiştir. Ancak bazı yerlerde Türbe çevresindeki piknik ve eğlenceden rahatsız olan ilgililer buna karşı ilan ve gazete haberleri ile tepkilerini göstermektedirler. Dolayısıyla Türbe ziyaretleri Anadolu da kutsal dua ve dilekler yanında bir araya gelme, toplanma, piknik yapma, eğlenme mekânı olarak da işlev görmektedir. Belediyeler tarafından yeni mimari de bu şekilde yapılmaktadır. Örneğin Malatya Darende' deki Somuncubaba türbesi çevresi, ziyaret yanında halkın piknik ve eğlence taleplerini karşılayacak şekilde yeniden dizayn edilmiştir. Piknik yerleri, yeme içme mekânları, kay kay, salıncak vb. imkânlar da hizmete koşulduğu görülmektedir. Buna benzer ülkemizden birçok örnek verilebilir.

Sonuç olarak, bu ve benzeri uygulamalara bakıldığında kutsal zaman ve mekânlarda yapılan uygulamaların aynı zamanda seküler bir içeriği de beraberinde taşıdığı görülmektedir. Bu kutsal mekân ve/veya zamanlarda eğlence de burada yerini almaktadır. Kutsal ile seküler bir arada iç içe bir görünüm arz etmekte ve işlev görmektedir. 


\section{Kaynakça}

Allen, D. (1987) "Phenomenology of Religion", The Encyclopedia of Religion, Mircae Eliade (ed.), C. 11, Macmillan, NewYork.

Arslan, M. (2002) Türk Popüler Dindarlı̆̆ı Üzerine Sosyolojik Bir Çalışma: Çorum Örneği, Yayımlanmamış doktora tezi, EÜ SBE, Kayseri.

Chidester and Linenthal (eds). (1995). American Sacred Space. Bloomington \& Indianapolis: Indiana University Press

Durkheim, E. (2005). Dini Hayatın İlkel Biçimleri, (Çev. F. Aydın), Ataç Yayınları, İstanbul.

Eliade, M. (1991) Kutsal ve Dindışı, (çev: M. Ali Kılıçbay), Gece Yayınları, Ankara.

Eliade, M. (1994) Ebedi Dönüş Mitosu, İmge Yayınları, İstanbul.

Eliade, M.(1959) Cosmos and History, Harper, New York.

Güngör, Erol (1981), “Eğlencenin Sosyal ve Psikolojik Yönü”, Türk Edebiyatı, C. 8, S. 94,

Ocak, A. Y. (1988) "Hıdrellez", İA, TDV İSAM, İstanbul, XVII, s. 313-5.

Ocak, A. Y. (1990) İslam Türk İnançlarında Hızır Yahut Hızır-İlyas Kültü, TKAE Yy. 113, 2. Basım, Ankara.

Otto R. (1925) The idea of the Holy, Trans. J.W. Harvey, Oxford Un. Press, Londra and New York.

Özdemir, N. (1999) "Eğlence Kavramı ve Hıdırellez Kutlamaları" Milli Folklor, C. 6, S. 42, s. 31-6.

Pettazzoni, R. (2002) Tanriya Dair, İz Yayınları, İstanbul.

Stirrat, R. L. (1984) “Sacred Models”, Man, Vol. 19, No. 2., pp. 199-215.

Tuzcuoğlu, H. (2008) Türkiye'de Dini Kesimin Eğlence Kültürü, Marmara

Üniversitesi Sosyal Bilimler Enstitüsü Yüksek Lisans Tezi, İstanbul.

http://corumhidirlik.corumlu.com/

http://www.aleviforum.net/Konu-hasan-basri-korucuk-turbesi.html 
http://bilecikhaber.com.tr/turbe-etrafinda-piknik-yapmayin http://3dpanoramik.com/panoramik/184/habib_i_neccar_camii_turbe. html

Abstract: -Between the Sacred and Secular: Entertainment Culture Emerging around Cults of Hidrellez and Ziyarat - In presentation we'll examine entertainment culture emerging around cults of Hidrellez and ziyarat that the two most important figures in Turkish folk beliefs and will discuss them within the framework of the sacredprofane dichotomy. In our earlier study we found cults of Muslim saints and Hidrellez between important figures of Turkish folk beliefs. These figures are also parallels with the syncretic nature of popular folk beliefs. It will be interesting to investigate. It will be interesting to investigate the rich and secular entertainment culture that emerging around these two beliefs and rituals as manifestations of the sacred (hierophany). Because, when looking beliefs and rituals emerging around the cults of ziyarat and Hidrellez in Turkish culture we see entertainments. Here it is important for the phenomenology of religion to see the various aspects of a secular phenomenon that occurs around the sacred. In our presentation we will address the "sacred" and "secular" nature of these entertainments. And we will study the entertainment culture formed around both the rituals separately address and will explain their functions in religious and social life. Because of wide of the subject we will take two cities (Malatya and Çorum) as the sample. In result we will compare these manifestations with theoretical models about sacred and secular, sacred-profane distinction and so on.

Key words: Sacred, Secular, entertainment, cults of Hidrellez and Ziyarat 